Complementarity:

Applications, Algorithms and Extensions 


\section{Applied Optimization}

Volume 50

Series Editors:

Panos M. Pardalos

University of Florida, U.S.A.

Donald Hearn

University of Florida, U.S.A.

The titles published in this series are listed at the end of this volume. 


\section{Complementarity: Applications, Algorithms and Extensions}

Edited by

Michael C. Ferris

Computer Sciences Department,

University of Wisconsin,

Madison, Wisconsin, U.S.A.

Olvi L. Mangasarian

Computer Sciences Department,

University of Wisconsin,

Madison, Wisconsin, U.S.A.

and

Jong-Shi Pang

Department of Mathematical Sciences,

The Johns Hopkins University,

Baltimore, Maryland, U.S.A.

Springer-Science + Business Media, B.V. 
A C.I.P. Catalogue record for this book is available from the Library of Congress.

Printed on acid-free paper

All Rights Reserved

ISBN 978-1-4419-4847-2 ISBN 978-1-4757-3279-5 (eBook)

DOI 10.1007/978-1-4757-3279-5

(C) 2001 Springer Science+Business Media Dordrecht

Originally published by Kluwer Academic Publishers in 2001.

Softcover reprint of the hardcover 1st edition 2001

No part of the material protected by this copyright notice may be reproduced or utilized in any form or by any means, electronic or mechanical, including photocopying, recording or by any information storage and retrieval system, without written permission from the copyright owner 


\section{Contents}

Preface

Approximating Maximum Stable Set and Minimum Graph Coloring

Problems with the Positive Semidefinite Relaxation

S. J. Benson \& Y. Ye

Nonmonotone Path Following Methods for Nonsmooth Equations and Complementarity Problems

Stephen C. Billups, Adam L. Speight \& Layne T. Watson

Scalable Probabilistic Clustering

P. S. Bradley, U. M. Fayyad \& C. A. Reina

A complementarity eigenproblem in the stability analysis of finite dimensional elastic systems with frictional contact

A. Pinto da Costa, I. N. Figueiredo, J. J. Júdice \& J. A. C. Martins

Variational Inequality Models of Restructured Electricity Systems

Olivier Daxhelet \& Yves Smeers

Optimization Approaches to Semi-Supervised Learning

Ayhan Demiriz \& Kristin P. Bennett

Preprocessing Complementarity Problems

Michael C. Ferris \& Todd S. Munson 
On the Connectedness of Solution Sets of Parametrized Equations and of Solution Sets in Linear Complementarity Problems

M. Seetharama Gowda, G.S.R. Murthy \& T. Parthasarathy

An Active Set-type Newton Method for Constrained Nonlinear Systems Christian Kanzow

Mathematical Programming in Engineering Mechanics: Some Current Problems

G. Maier, G. Bolzon E F. Tin-Loi

Data Discrimination via Nonlinear Generalized Support Vector Machines

O. L. Mangasarian \& David R. Musicant

On Constraint Qualifications for Mathematical Programs with Mixed Complementarity Constraints

J. V. Outrata

A Generation Operation Planning Model in Deregulated Electricity Markets based on the Complementarity Problem

Michel Rivier, Mariano Ventosa, Andrés Ramos, Francisco Martinez-Córcoles \& Ángel Chiarri Toscano

A Class of Globally Convergent Algorithms for Pseudomonotone Variational Inequalities

M. V. Solodov

Successive Convex Relaxation Approach to Bilevel Quadratic Optimization Problems

Akiko Takeda \& Masakazu Kojima

On a Nonsmooth Newton Method for Nonlinear Complementarity Problems in Function Space with Applications to Optimal Control Michael Ulbrich

The Proximal Point Algorithm for the $P_{0}$ Complementarity Problem

Nobuo Yamashita, Junji Imai \& Masao Fukushima

Free Boundary Problems in Asset Pricing with Transaction Costs 


\section{Preface}

This volume presents state-of-the-art complementarity applications, algorithms, extensions and theory in the form of eighteen papers. These invited papers were presented at the International Conference on Complementarity 99 (ICCP99) held in Madison, Wisconsin during June 9-12, 1999 with support from the National Science Foundation under Grant DMS-9970102.

Complementarity is becoming more widely used in a variety of application areas. In this volume, there are papers studying the impact of complementarity in such diverse fields as deregulation of electricity markets, engineering mechanics, optimal control and asset pricing. Furthermore, application of complementarity and optimization ideas to related problems in the burgeoning fields of machine learning and data mining are also covered in a series of three articles.

In order to effectively process the complementarity problems that arise in such applications, various algorithmic, theoretical and computational extensions are covered in this volume. Nonsmooth analysis has an important role to play in this area as can be seen from articles using these tools to develop Newton and path following methods for constrained nonlinear systems and complementarity problems. Convergence issues are covered in the context of active set methods, global algorithms for pseudomonotone variational inequalities, successive convex relaxation and proximal point algorithms.

Theoretical contributions to the connectedness of solution sets and constraint qualifications in the growing area of mathematical programs with equilibrium constraints are also presented. A relaxation approach is given for solving such problems. Finally, computational issues related to preprocessing mixed complementarity problems are addressed.

The use of complementarity within other problem types, such as bilevel optimization and data mining is considered. Positive semidef- 
inite relaxations are a new and growing area of research that has significant ramifications for discrete optimization. These and other application specific extensions of the field are also covered in this volume.

It is hoped that the results presented here will inspire further contributions to the field of complementarity, especially in the form of novel applications and computational techniques with significant underlying theory.

Michael Ferris, Olvi MaNGaSaRian AND JoNG-Shi PaNG 